\title{
Redescobrindo a Ginástica Acrobática
}

\author{
Fernanda Merida* \\ Vilma Lení Nista-Piccolo** \\ Marcos Merida***
}

\begin{abstract}
Resumo: Ginástica Acrobática é a mais jovem modalidade do universo ginástico competitivo, cuja prática apresenta grande valor pedagógico, embora tenha sido pouco estudada no ambiente acadêmico com poucos registros dos conhecimentos adquiridos por seus acrobatas e ginastas ao longo dos tempos. Este artigo de revisão tem como objetivo impulsionar o redescobrimento da Ginástica Acrobática, como objeto de estudos acadêmicos, prática esportiva e conteúdo da Educação Física escolar. Para isto, serão abordados o cenário da modalidade no mundo, o seu percurso histórico, suas características e especificidades e alguns princípios pedagógicos com base nos autores mais relevantes para o tema.
\end{abstract}

Palavras-Chave: Ginástica Acrobática. Revisão de Literatura. Esportes: história.

\section{INTRODUÇÃO}

A Ginástica Acrobática (GACRO), terminologia adotada oficialmente a partir do ciclo competitivo 2005/2008, é também conhecida como Acrosport e Esportes Acrobáticos.

Em 2007, a GACRO faz 33 anos de existência como modalidade esportiva, o que nos permite considerá-la relativamente jovem. Muitos autores argumentam que, por ser uma modalidade recémchegada no mundo da competição, ainda não recebeu atenção acadêmica. Apesar do imenso conhecimento acumulado pelos acrobatas ao longo dos tempos, estas informações não foram registradas e publicadas, acarretando uma escassez bibliográfica, que aparecem,

"Prof ${ }^{a}$ Mestranda. Mestrado em Educação Física. Universidade São Judas Tadeu. São Paulo, SP, Brasil. E-mail: fmerida@uol.com.br

"Prof ${ }^{a}$ Doutora. Doutorado em Psicologia Educacional. Universidade São Judas Tadeu/ Metrocamp, São Paulo/Campinas, SP, Brasil. E-mail: vilma@ nista.com.br

"* Prof. Mestrando. Mestrado em Educação. Universidade Presbiteriana Mackenzie. São Paulo, SP, Brasil. E-mail: mmerida@mackenzie.com.br 
em sua maioria, com um caráter histórico, com alguns manuais bastante falhos e com pouco valor pedagógico (ASTOR, [1954?]; HUGHES; CROWLEY, 2001). Acrescenta-se que a motivação da sociedade para determinadas modalidades esportivas, fatores que estão relacionados à cultura de cada país, também podem influenciar na disseminação das mesmas.

A GACRO diferencia-se das outras modalidades ginásticas pelo fato de proporcionar trabalhos em grupo, por necessitar de poucos materiais, resultando em menor custo, além de poder ser desenvolvida com ginastas de diferentes estruturas físicas.

Tendo em vista, então, os poucos registros referentes a esta modalidade, a sua disseminação ainda reduzida e as grandes vantagens que a prática da GACRO oferece, questiona-se: o que tem sido estudado com relação à modalidade no mundo?

Assim, o objetivo deste estudo é (re)apresentar a GACRO no contexto acadêmico, pontuando o que se tem de registro sobre ela, os estudos realizados, a sua trajetória histórica, suas características e possibilidades para o universo esportivo. Em outras palavras, intenciona-se impulsionar o redescobrimento desta modalidade gímnica, por meio de uma síntese dos trabalhos publicados mais relevantes.

\section{Cenário da Ginástica Acrobática}

Neste momento, é necessário situar a GACRO no panorama mundial, levando-se em conta os estudos acadêmicos que se referem a esta prática, elencando os aspectos apontados pelos mesmos, identificando as instituições que organizam a sua prática e quais países têm se mostrado mais envolvidos com a modalidade.

O levantamento bibliográfico foi realizado a partir do Google Acadêmico, das bases de dados ABI Inform Archive, Cambridge Scientific Abstracts (CSA), Evidence Based Medicine (EBM), COCHRANE da Biblioteca Virtual de Saúde (BVS), Scientific Electronic Library Online (SciELO), ProQuest Research Library,

Mavimento, Porto Alegre, v. 14, n. 02, p. 155-180, maio/agosto de 2008. 
PUBMED, Excerpta Medica database (EMBASE), Literatura LatinoAmericana e do Caribe em Ciências da Saúde (LILACS), EBSCHO, QUEST e The Educational Resources Information Center (ERIC) e dos catálogos das bibliotecas da Escola de Educação Física e Esporte da Universidade de São Paulo (São Paulo, SP), da Universidade Presbiteriana Mackenzie (Campus Tamboré, Barueri, SP) e da Universidade São Judas Tadeu (Campus Moóca, São Paulo, SP). Foram analisadas todas as bases disponibilizadas nas instituições escolhidas, tanto catalográficas quanto virtuais. Tendo em vista a indisponibilidade de acesso a determinadas bases de dados em instituições particulares, optou-se também por consultar uma instituição pública, na qual o acesso às bases de dados é irrestrito, procurando a maior abrangência possível na revisão bibliográfica em questão. Nenhum período foi privilegiado, buscando-se atingir a totalidade de publicações sobre esta temática. O gráfico abaixo mostra o pequeno número de publicações acadêmicas encontradas, questão apontada por diversos autores:

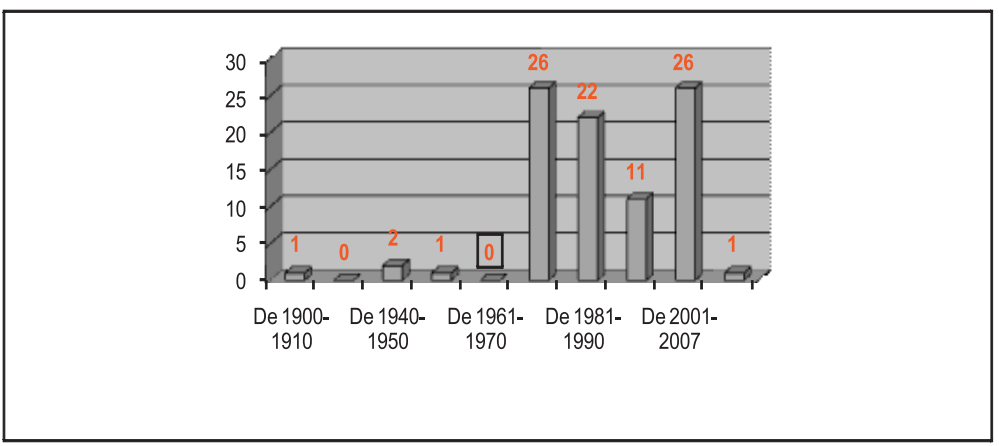

Gráfico 1 - Publicações acadêmicas encontradas no mundo.

Os estudos encontrados até 1970 são livros ou parte de livros que se referem às acrobacias realizadas em duplas e em pequenos grupos, e não à Ginástica Acrobática como modalidade esportiva, visto que sua implantação deu-se junto à fundação da Federação Internacional de Esportes Acrobáticos (IFSA), ocorrida em 1973.

A partir do primeiro campeonato mundial da modalidade, em 1974, houve um aumento no número de publicações (artigos acadêmicos, artigos em revistas especializadas e livros) até o final da

Mavimento, Porto Alegre, v. 14, n. 02, p. 155-180, maio/agosto de 2008. 
década de 1980. Estas publicações tinham um cunho de incentivo e disseminação, de apresentação e explicação do que era a modalidade e seus princípios pedagógicos. Portanto, os estudos eram abrangentes e o foco principal era a modalidade.

Friend (1990a) colabora com este panorama ao afirmar que muitos clubes e atletas, na época, estavam oferecendo e praticando a GACRO, e as revistas e a mídia em geral interessavam-se por artigos e matérias sobre o tema.

Na década de 1990, o número de estudos começa a diminuir, possivelmente pela não inserção da modalidade no programa dos Jogos Olímpicos, o que, em certa medida, pode ser um dos fatores que tem corroborado para a pouca expressão que a mesma apresenta no cenário esportivo.

Já no período de 2001 a 2007, apesar do número de publicações ter aumentado, é preciso levar em conta o aumento da produção científica no mundo, ou seja, comparando-se com o número de trabalhos acadêmicos em geral, respectivamente ao aumento dos programas de pós-graduação no mundo todo, podemos dizer que este número é muito pequeno. Além disso, a maioria das obras publicadas neste período não apresenta preocupações pedagógicas, mas são de ordem biológica, biomecânica ou ainda, demasiadamente específicas às questões técnicas.

No que se refere à produção acadêmica, os países europeus, em especial Espanha, França e Portugal, têm sido os que mais produzem estudos e pesquisas focados na GACRO, além da Austrália, China e Estados Unidos

Com relação à prática desta modalidade, os países que mais têm se destacado nos últimos campeonatos mundiais são a Rússia, a Ucrânia, a China e os Estados Unidos.

Atualmente, a Ginástica Acrobática e todas as outras modalidades gímnicas estão subordinadas à Ginástica que, no Brasil, está organizada, verticalmente, pelas seguintes instituições, seguindo o proposto por Brasil (1998) no artigo 13, da lei no 9.615, de 24 de março de 1998:

Movimento, Porto Alegre, v. 14, n. 02, p. 155-180, maio/agosto de 2008. 


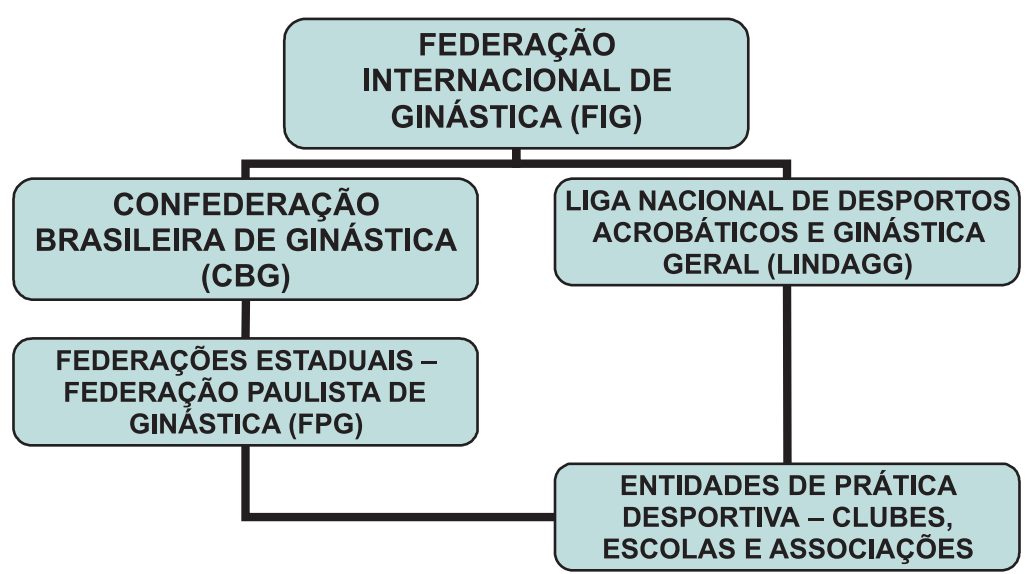

Figura 1 - Organização administrativa da Ginástica.

Portanto, de acordo com o organograma, a FIG, a CBG, a LINDAGG e as Federações Estaduais de Ginástica são as entidades que detêm a autoridade sobre as questões da Ginástica, cada qual com sua respectiva abrangência. As ações realizadas têm se restringido à organização de calendários, competições e cursos técnicos e de arbitragem de curta duração, embora todas elas tenham se comprometido, em seus estatutos próprios, a organizarem congressos, pesquisas e supervisões de seus árbitros.

A responsabilidade pelo fomento e organização de todas as modalidades ginásticas, a saber, a Ginástica Artística (GA), a Ginástica Rítmica (GR), a Ginástica de Trampolim (GT), a Ginástica Aeróbica (GAE), a Ginástica Acrobática (GACRO) e a Ginástica Geral (GG), pode ser apontado como um fator que tem prejudicado a qualidade das ações das entidades. É possível notar que a GA e a GR têm sido priorizadas, devido à maior tradição e repercussão de ambas em competições internacionais. Outro ponto que favorece o desenvolvimento das modalidades olímpicas é a verba que o Comitê Olímpico Brasileiro (COB) repassa para a Ginástica Artística Masculina e Feminina, Ginástica Rítmica e Ginástica de Trampolim que integram o programa das Olimpíadas desde 1908, 1928, 1984 e 2000 , respectivamente.

Mavimento, Porto Alegre, v. 14, n. 02, p. 155-180, maio/agosto de 2008. 
No cenário internacional, as confederações de países como os EUA e Portugal oferecem programas de formação e acompanhamento da evolução dos técnicos, ações voltadas aos atletas como acampamentos com objetivos de treinamento, entre outras atividades enriquecedoras para o crescimento da modalidade.

\section{Características da Ginástica Acrobática}

A GACRO tem três princípios fundamentais que a caracterizam: a formação de figuras ou pirâmides humanas; a execução de acrobacias, elementos de força, flexibilidade e equilíbrio para transitar de uma figura à outra; a execução de elementos de dança, saltos e piruetas ginásticas como componente coreográfico.

A diferença entre praticar a GACRO e outras modalidades gímnicas está no fato de as propostas estarem mais voltadas aos trabalhos entre os grupos de ginastas do que em performance com aparelhos, embora existam muitos elementos em comum, como o tumbling (seqüência de exercícios acrobáticos), a força, a flexibilidade, o equilíbrio e a presença de uma coreografia (CRILEY, 1984; BOELSEMS, 1982; NISSEN, 1991).

A GACRO necessita de poucos materiais e tem baixo custo, se comparada às demais modalidades ginásticas (ALMEIDA, 1994; CRILEY, 1984; NISSEN, 1991). Em situações competitivas, são utilizados somente o tablado e os colchões de segurança ou de lançamento; nos treinamentos, colchões simples, cintos de auxílio, pedestais, medicine balls e simuladores de parceiros, além de materiais de apoio como plintos, espaldares, cavalos, entre outros.

Outro diferencial é que a modalidade pode ser desenvolvida com ginastas de diferentes estruturas físicas. Esta característica particular permite a longevidade da participação esportiva e pode desencorajar a especialização precoce que, não raras vezes, ocorre em certas modalidades esportivas.

Quanto aos seus benefícios, os praticantes desta modalidade podem ser favorecidos pela aquisição de noções espaço-temporais, da esquematização corporal, do controle motor, da flexibilidade, da

Movimento, Porto Alegre, v. 14, n. 02, p. 155-180, maio/agosto de 2008. 
coordenação estática, da coordenação coletiva, do equilíbrio, da força e da resistência muscular localizada, da cooperação, da autonomia, do prazer e da autoconfiança (ALMEIDA, 1994; ASTOR, [1954?]). Além disso, experiências corporais valiosas e enriquecedoras para a cultura corporal do homem são conseguidas por meio da prática das atividades ginásticas (LEGUET, 1987; SOARES, 1998; SOUZA, 1997; GALLAHUE; OZMUN, 2005).

Nissen (1991, p. 36-37) aponta vinte vantagens da GACRO com relação às demais modalidades ginásticas competitivas. As mais relevantes estão explanadas abaixo:

- Idade ${ }^{l}$ : não há limite de idade e muitos atletas de alto rendimento têm sua carreira estendida até os 30 anos;

- Peso corporal e biótipo: não há pressão para manter o peso baixo, pois os bases, atletas que sustentam as pirâmides, podem ter um peso corporal maior. Além disso, não há um padrão de corpo (biótipo) exigido o que torna a carreira em GACRO mais longa;

- Cooperação: por ser uma modalidade realizada em grupos e necessitar de interação entre os participantes, a rivalidade pessoal é diminuída;

- Sociabilização: não há divisão entre sexos nos treinamentos, sendo assim, a co-educação diminui os preconceitos de gêneros e de diferenças individuais;

- Sincronismo: por todas as provas serem realizadas em duas ou mais pessoas, a preocupação com o sincronismo das ações é freqüente, melhorando o trabalho em equipe;

- Atratividade dos espectadores e da mídia: devido ao trabalho de grupos, maiores alturas, variedades de movimentos e posições são demonstradas, atraindo os espectadores e, conseqüentemente, a mídia;

- Oportunidades: por ser uma modalidade jovem, o mercado ainda não está saturado e chegar ao alto nível parece ser mais acessível. Além disso, o mercado de trabalho para técnicos, árbitros e dirigentes está em expansão;

${ }^{1}$ Os termos em itálico foram traduzidos do autor original.

Mavimento, Porto Alegre, v. 14, n. 02, p. 155-180, maio/agosto de 2008. 
- Ambientes: por não necessitar de aparelhagem, apenas dos parceiros, a GACRO pode ser praticada em praias e gramados, por exemplo;

- Imagem: não há o preconceito social de que não é uma atividade para homens e muitos deles se fascinam pela idéia de levantar meninas ao invés de pesos;

- Programas: muitos ginastas aposentados de outras modalidades podem ser inseridos no programa de GACRO ampliando as possibilidades para clubes, escolas e associações;

- Equipes: o número de participantes das equipes é grande (13 atletas), ampliando as possibilidades para os ginastas.

Por estes fatores, a Ginástica Acrobática tem se legitimado como uma modalidade esportiva relevante para o universo ginástico e esportivo, preenchendo algumas lacunas importantes, deixadas por outras modalidades ginásticas competitivas.

Além disso, alguns autores apontam as contribuições da GACRO para a dança e para as líderes de torcida, mais presentes na cultura americana (DOUGLAS, 1982; FRIEND, 1990b). Acrescentamos ainda, as contribuições para as outras modalidades ginásticas, especialmente para a Ginástica para todos e para a Ginástica Aeróbica.

\subsection{Breve histórico da modalidade}

O conceito de Ginástica recebeu diferentes conotações ao longo da história. Os gregos entendiam a ginástica como sinônimo de exercícios físicos em geral, como as corridas, as lutas, a equitação, os saltos, entre outros. Soares (1998) afirma que as primeiras formas organizadas de Ginástica se realizavam através dos jogos, da equitação, da esgrima, dos exercícios militares, das corridas, das danças e dos cantos, dos saltos e das acrobacias.

De acordo com Astor ([1954?]), nos mais antigos monumentos do Egito foram gravadas cenas do cotidiano da Antigüidade, as quais incluíam os exercícios acrobáticos, atividades precursoras da GACRO.

$\mathrm{Na}$ Grécia antiga, a acrobacia desenvolveu-se ao lado das demais artes e foi representada em diversos vasos pintados, estátuas, cerâmicas e murais da época.

Movimento, Porto Alegre, v. 14, n. 02, p. 155-180, maio/agosto de 2008. 
Na Roma antiga, o circo romano não possuía acrobatas e seu programa constava, geralmente, de corrida de bigas, combates de gladiadores, provas de atletismo e exibições de feras. No entanto, os ricos patrícios possuíam suas "troupes" particulares que cantavam, dançavam e executavam acrobacias.

No resto do mundo, a acrobacia parecia progredir também, principalmente na China e na Índia que tiveram acrobatas de valor indiscutível, segundo Astor ([1954?]) além do Japão, que conserva sua tradição acrobática até os dias de hoje.

Durante a Idade Média, os exercícios acrobáticos mantiveram o seu nível de expansão, graças a pequenas "troupes" ambulantes que viajavam de cidade em cidade, de castelo em castelo, executando números acrobáticos e recitando poesias e canções.

O continente americano também parece ter contribuído para a acrobacia, pois de acordo com o mesmo autor, os historiadores europeus contam que, em 1519, Fernão Cortez assistiu, na cidade do México, à demonstração de um funâmbulo nativo, o qual impressionou os espanhóis com sua habilidade.

No século XVI, foram publicadas, na Europa, as primeiras obras técnicas sobre acrobacia, porém a bibliografia da acrobacia começou a se desenvolver somente a partir de 1920.

Segundo Langlade e Langlade (1970), a configuração da Ginástica nos moldes que a conhecemos hoje, ocorreu por volta de 1800. Entre 1800 e 1900, surgiram e se desenvolveram as Escolas Ginásticas:

- Escola inglesa (voltada para os jogos, atividades atléticas e esportivas);

- Escola alemã (pregava a prática da Ginástica de caráter militar e foi a precursora da ginástica artística);

- Escola sueca (vista como eliminadora de vícios posturais e da sociedade, possuía caráter pedagógico e social e foi adotada por diversos estabelecimentos de ensino);

- Escola francesa (apresentada a intenção de formar o homem universal, voltada para a educação e o desenvolvimento social).

Mavimento, Porto Alegre, v. 14, n. 02, p. 155-180, maio/agosto de 2008. 
Em seguida, passaram a existir os Movimentos Ginásticos: o do Centro, o do Norte e o do Oeste, que promoveram alterações nos métodos desenvolvidos pelas Escolas Ginásticas, perdurando até 1939, como afirmam os mesmos autores. A partir daí, iniciou-se um período de influências recíprocas e universalização dos sistemas ginásticos.

É em 1939 que a acrobacia dá lugar a uma modalidade esportiva que começa a ser moldada a partir do campeonato de "mano a mano", tido como o precursor do Acrosport (POZZO; STUDENY, 1987).

Já na década de 50, ginastas, bailarinos e artistas de circo da Polônia, Bulgária e da antiga União Soviética organizaram turnês de shows itinerantes com práticas ginásticas que também influenciaram o Acrosport (BROZAS; NOWOTYNSKY, 2002).

O primeiro campeonato mundial foi realizado em 1974, em Moscou, e desde então, ela faz parte do programa dos Campeonatos Mundiais, mas ainda não está inserida no programa dos Jogos Olímpicos.

Conforme Souza (1997b), o corpo administrativo internacional, Federação Internacional de Esportes Acrobáticos (IFSA) foi fundado em 1973, mas em 1998 foi fundido com a Federação Internacional de Ginástica (FIG), como apresentado anteriormente.

Atualmente, diversas formas de ginástica compõem o universo ginástico, dentre elas as ginásticas competitivas, e dentre as quais se encontra a Ginástica Acrobática que, como modalidade esportiva competitiva é relativamente jovem.

\subsection{Provas e funções específicas dos ginastas}

De acordo com o código de pontuação da Ginástica Acrobática 2005-2008, da FEDERAÇÃO INTERNACIONAL DE GINÁSTICA, a Ginástica Acrobática é praticada por pares masculinos, femininos ou mistos, por grupos femininos (composto por três ginastas), ou seja, trios femininos, como são chamados no Brasil e por grupos masculinos (composto por quatro ginastas), isto é, quartetos masculinos na nomenclatura nacional.

Movimento, Porto Alegre, v. 14, n. 02, p. 155-180, maio/agosto de 2008. 
No entanto, vale ressaltar que, fora do âmbito competitivo, os grupos destas provas não precisam ser obedecidos. Desta forma, as pirâmides humanas podem ser formadas por um número qualquer de atletas, o que amplia o repertório de criação e as possibilidades de execução das mesmas (MERIDA, 2004).

As pirâmides humanas são formadas por ginastas que recebem um nome de acordo com as funções específicas que executam. $\mathrm{O}$ base é o ginasta que suporta e projeta seus companheiros. O intermediário é o ginasta que ajuda a suportar e projetar ou que executa posições intermediárias. $\mathrm{O}$ volante ou top é o ginasta que é suportado e projetado pelos demais e freqüentemente está no topo das pirâmides. Cada pirâmide pode conter um ou mais ginastas de cada função, de acordo com o número de participantes e com o desenho que pretendem formar no espaço.

Estas funções desempenhadas pelos ginastas são definidas de acordo com a sua estrutura e capacidades físicas, prioritariamente, além do fator idade, que também pode interferir na escolha da função específica. Nas competições oficiais, existem regras que relacionam a altura e a idade dos ginastas para definir as funções específicas e categorias de cada $\mathrm{um}^{2}$.

Devem-se aliar ao máximo, estas questões biológicas às necessidades e expectativas dos ginastas com relação à escolha das funções e dos parceiros.

A este respeito, Criley (1982), em seus comentários sobre o livro Esportes Acrobáticos de Jill Coulton (1981), afirma que os exercícios de GACRO envolvem interação e requerem confiança mútua e cooperação, mas o estresse também pode se mostrar presente neste cenário. Desta forma, a escolha do parceiro não deve se basear somente nos aspectos físicos, mas também na personalidade.

Quanto às características das funções anteriormente explanadas, a literatura sugere que "os bases" são geralmente os ginastas mais velhos, pesados e fortes e devem possuir a capacidade de ajustar o

${ }^{2}$ De acordo com o CÓDIGO DE PONTUAÇÃO DE DESPORTOS ACROBÁTICOS (FIG, 2002), a pessoa mais baixa do par/grupo não pode ser mais baixa que o ponto supra-esternal do seu parceiro (par) ou do parceiro mais próximo do seu tamanho (grupos).

Mavimento, Porto Alegre, v. 14, n. 02, p. 155-180, maio/agosto de 2008. 
equilíbrio dos volantes e zelar pela sua segurança. "Os volantes" são geralmente os ginastas mais jovens, leves, flexíveis e ágeis. Também são fortes e devem ser capazes de realizar acrobacias com grande senso cinestésico e não devem ter medo de alturas. Já "os intermediários" devem ser mais leves que o base, e demonstrar a combinação de todos estes atributos (SANTANA et al, 1996; CRILEY, 1984; FEDERAÇÃO NORTE AMERICANA, 2007).

De maneira simplificada, Almeida (1994) sugere que a diferença de peso corporal deva ser, no mínimo, de 15 quilos, o que evitaria possíveis lesões ou malformações nos praticantes.

Já Criley (1984) sugere diferenças de peso e altura mais detalhadas entre os ginastas de acordo com as provas que executam:

- Duplas masculinas: altura de $15-20 \mathrm{~cm}$ e peso de $15-20 \mathrm{~kg}$;

- Duplas femininas: altura de $10-20 \mathrm{~cm}$ e peso de $10-15 \mathrm{~kg}$;

- Pares mistos: altura de $20-25 \mathrm{~cm}$ e peso de $20-25 \mathrm{~kg}$;

Este autor não cita as provas de trios e quartetos, porém, acredita-se que estas diferenças podem nortear as demais definições de diferenças de peso e altura nos trios e quartetos.

\subsection{Rotinas obrigatórias}

O código de pontuação de Ginástica Acrobática 2005/2008, elaborado pela FEDERAÇÃ̃ INTERNACIONAL DE GINÁSTICA, estabelece que as rotinas (séries ou exercícios) sejam realizadas com música, sem letra, mas que a voz pode ser utilizada como instrumento, exceto na prova de quarteto masculino.

O mesmo documento regulamenta que o tempo permitido para as séries estáticas e dinâmicas seja de, no máximo, dois minutos e meio, não sendo estipulado tempo mínimo. Para as séries combinadas o tempo máximo é de três minutos. Quanto à área de competição, é utilizado um tablado, que deve medir 12 x 12 metros.

As séries devem incluir uma combinação harmoniosa de coreografia, elementos de acrobacia coletiva, ou seja, figuras e elementos individuais, tudo em perfeito sincronismo.

Movimento, Porto Alegre, v. 14, n. 02, p. 155-180, maio/agosto de 2008. 
As competições de Ginástica Acrobática devem conter as seguintes rotinas e elementos individuais, obrigatoriamente:

- Elementos individuais são elementos que cada ginasta deve executar individualmente durante as séries:

a) Tumbling (exercícios acrobáticos realizados em seqüência sem interrupção);

b) Flexibilidade;

c) Equilíbrio (manutenção de dois segundos);

d) Coreográficos;

- Rotina estática (ou Balance) é uma série composta por pirâmides estáticas, cujos ginastas permanecem em contato durante todo o tempo de permanência da figura. O tempo de permanência nas figuras estáticas varia de dois a quatro segundos de acordo com a prova.

- Rotina dinâmica (ou Tempo) é uma série composta por elementos dinâmicos. Os exercícios dinâmicos têm que demonstrar fases de vôo, lançamentos e recepções e são definidos por cinco categorias de elementos:

a) De parceiro para parceiro;

b) Do chão para o parceiro;

c) Do parceiro para o chão;

d) Do parceiro para o chão, após um breve contato com o parceiro;

e) Do chão, com uma breve assistência do parceiro, para o chão outra vez (elemento dinâmico "puro");

- Rotina combinada é uma série composta por elementos individuais, estáticos e dinâmicos combinados.

Quanto à avaliação das rotinas, o valor técnico (de dificuldade) das figuras são os mais valorizados, embora os árbitros também valorizem a originalidade dos exercícios (BROZAS; NOWOTYNSKI, 2002).

Os seis árbitros e os auxiliares avaliam as séries pelos seguintes quesitos: valor de dificuldade dos exercícios, composição das séries, execução das séries (incluindo recepções), impressão geral

Wavimento, Porto Alegre, v. 14, n. 02, p. 155-180, maio/agosto de 2008. 
(incluindo coreografia, execução artística, música), tempo (duração) das séries e tempo de manutenção dos equilíbrios (exercícios estáticos e combinados) (FEDERAÇÃO PAULISTA DE GINÁSTICA).

Este estudo pretende apenas apresentar as características das rotinas para que uma compreensão global acerca da modalidade seja possível e, portanto, não intenciona detalhar mais os aspectos competitivos. Outras informações sobre tais aspectos, tanto relacionados à avaliação dos árbitros, quanto aos valores de dificuldade das figuras, podem ser encontrados no código de pontuação de Ginástica Acrobática do ciclo 2005-2008.

\subsection{Monte e Desmonte}

Segundo Almeida (1994), "monte" é um elemento técnico no qual o(s) ginasta(s) sobe $(\mathrm{m})$ para o(s) parceiro(s), podendo descrever uma fase de vôo ou aproveitando os segmentos do parceiro como apoios para a subida, sem perder contato com o mesmo.

Em respeito ao "desmonte", este é um elemento técnico no qual $\mathrm{o}(\mathrm{s})$ ginasta(s) perde $(\mathrm{m})$ o contato com o(s) parceiro(s), existindo uma fase de vôo prévia entre a projeção e recepção. Um desmonte deverá ser sempre seguro e reduzir ao máximo os riscos de queda.

Merida (2004) afirma que o monte e o desmonte de uma mesma figura podem ser realizados de diversas maneiras. Desta forma, o professor ou técnico deve incentivar a criatividade de seus alunos, permitindo a execução de uma grande variedade destes elementos técnicos. No entanto, deve priorizar a segurança e a seleção das "pegas e lançamentos" mais adequados para cada figura.

\subsection{Técnicas de Pegas e Suportes}

"Pegas ou pegadas" são as maneiras como as mãos são posicionadas no parceiro para facilitar a subida (monte), a execução (manutenção) e a descida (desmonte) das pirâmides. A palavra suporte é utilizada para tais posicionamentos nos lançamentos, isto é, nos exercícios dinâmicos.

Movimento, Porto Alegre, v. 14, n. 02, p. 155-180, maio/agosto de 2008. 
O conhecimento das "pegas" e "suportes"3 (ALMEIDA, 1994), e de suas vantagens e desvantagens, de acordo com o tipo de figura e posicionamento do corpo, são fundamentais não só para maximizar a eficiência das subidas, lançamentos e descidas das figuras, mas também para primar pela segurança dos ginastas.

Torna-se evidente que os técnicos e os ginastas devem dominar este tema, para identificar a melhor pega para cada ocasião e para planejar suas ações. Para cada figura, pode-se utilizar uma ou mais pegas ou suportes que se adequiem melhor, propiciando uma maior estabilidade, impulsão e segurança.

As principais pegas que constam na literatura são:

1. Pega de punhos: é utilizada, principalmente, quando os ginastas seguram-se com apenas uma das mãos, porém existem várias formas de utilizá-la e é muito segura.

\section{Ilustração 2:}

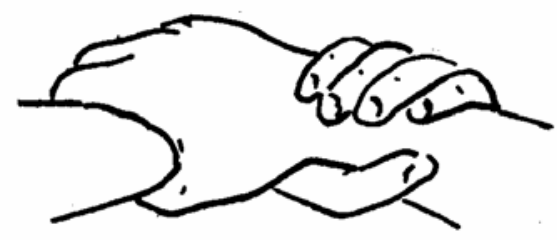

2. Pega de dedos: é menos segura que a anterior, porém permite maior mobilidade.

Ilustração 3:

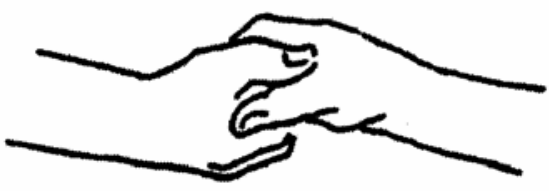

${ }^{3}$ Outras nomenclaturas são encontradas na literatura para identificar os mesmo movimentos,
são elas: pegadas (SANTOS, 2002), grips (CRILEY, 1984) ou hand grips (FODERO e FURBLUR, 1989).

Mavimento, Porto Alegre, v. 14, n. 02, p. 155-180, maio/agosto de 2008. 
3. Pega de palmas (ou aperto de mãos): utilizada nas figuras que os ginastas se encontram lado a lado, em direções opostas, ou quando o volante está de frente ou de lado para aquele que é base e se movimenta para trás dele. Utilizam-se mãos homônimas.

Ilustração 4:

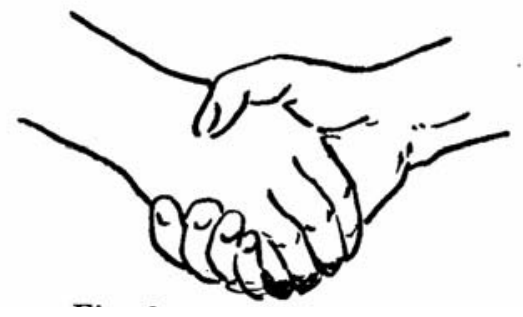

4. Pega de braços (ou ombros): os ginastas seguram-se mutuamente pelos braços, o base segura o volante pela parte interna do braço e o volante pela externa.

Ilustração 5:

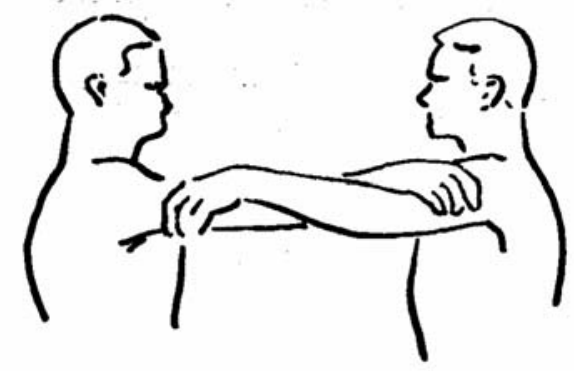

5. Pega de antebraço (ou cotovelos): os ginastas seguram-se mutuamente pelos cotovelos, o elemento-base segura o volante pela parte externa do braço e o volante pela interna.

Ilustração 6:

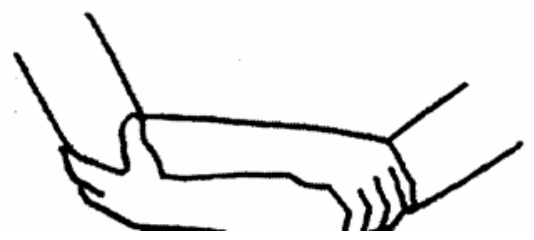

Movimento, Porto Alegre, v. 14, n. 02, p. 155-180, maio/agosto de 2008. 
6. Pega de palmas com preensão de polegares: muito executada em transições e contra balanceios, é muito segura e utilizam-se mãos homônimas.

Ilustração 7:

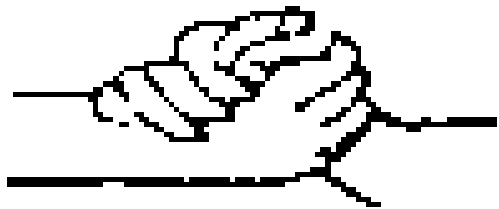

7. Pega de palmas com preensão de dedos nos punhos (ou pega de tesoura): bastante realizada em figuras com apoio invertido e geralmente com o punho estendido.

Ilustração 8:

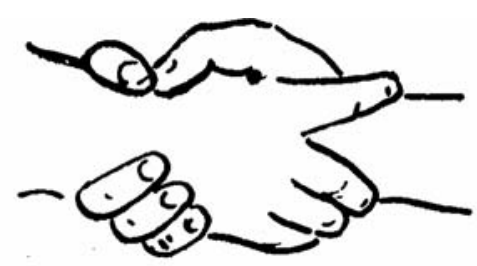

8. Pega atravessada: quando volante e base estão frente à frente e utilizam mãos não homônimas para se sustentarem.

Ilustração 9:

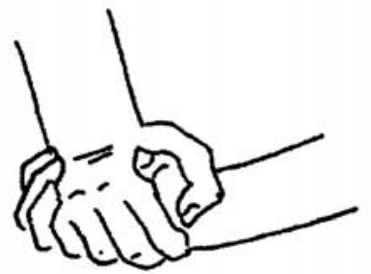

Mavimento, Porto Alegre, v. 14, n. 02, p. 155-180, maio/agosto de 2008. 
9. Pega de mãos com dedos apoiados no punho: similar à pega de tesoura, porém mais confortável.

Ilustração 10:

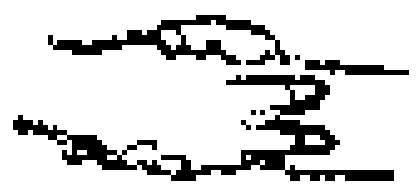

10. Pega pé e mãos: o apoio deve ocorrer na curvatura dos pés, entre a ponta e o calcanhar, servindo de suporte ou de impulsão para o volante.

Ilustração 11:

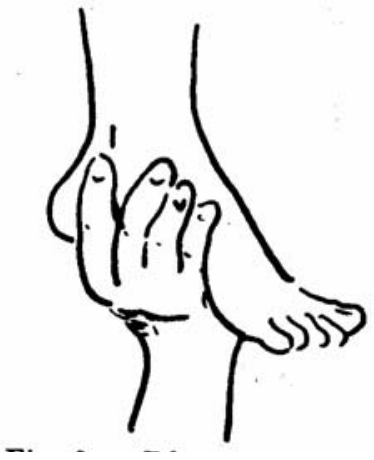

11. Suporte para estafa: auxilia a impulsão dos ginastas para executar exercícios dinâmicos, lançamentos para mortais e piruetas. $\mathrm{O}$ base, com as mãos sobrepostas, impulsiona o volante.

Ilustração 12:

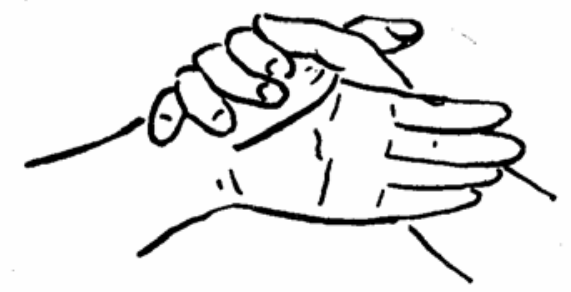

Movimento, Porto Alegre, v. 14, n. 02, p. 155-180, maio/agosto de 2008. 
12. Pega entrelaçada (ou cadeirinha): utilizada em trios e quartetos para executar exercícios dinâmicos, lançamentos para mortais e piruetas.

Ilustração 13:

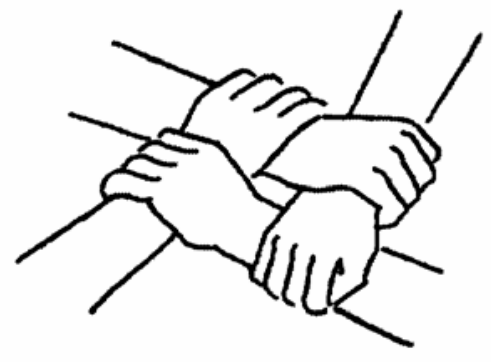

Uma mesma pega pode ser conhecida nos ambientes de treinamento por diferentes nomes, o mesmo ocorre na literatura. Sendo assim, optou-se neste estudo, por mesclar nomenclaturas de três autores (SANTOS, 2002; CRILEY, 1984; ALMEIDA, 1994), juntamente com a nomenclatura popular, visto que cada um contribui com um nome mais adequado para determinada pega.

\subsection{Segurança}

Foram apresentadas as funções, as provas, as rotinas e as pegas da GACRO para situar a prática pedagógica. Além disso, é preciso conhecer as principais medidas de segurança da GACRO para garantir uma atuação responsável e a integridade dos alunos, a saber:

- O atleta deve ter a capacidade de sair sozinho de situações perigosas, executando as quedas de forma correta (arredondamento do tronco e grupamento dos membros);

- O atleta base precisa conhecer bem a técnica de execução dos exercícios para saber a melhor forma de segurar o volante e de privar por sua segurança;

- O volante e os intermediários devem conhecer todo o movimento para saber a melhor forma de descer ou se proteger na queda;

- O treinador precisa conhecer seus alunos para identificar as qualidades físicas dos atletas, visando prever a falta de coragem, de

Mavimento, Porto Alegre, v. 14, n. 02, p. 155-180, maio/agosto de 2008. 
força de vontade, ou ainda, para compensar a falta de técnica e de evolução física;

- Durante os treinamentos é necessário criar condições ideais de aterrissagem, evitando a impactação excessiva;

- Os atletas devem executar somente o que foi planejado anteriormente pelo técnico ou por seu grupo.

Astor ([1954?]) aponta para outras medidas de segurança que envolvem ações pedagógicas, a saber: explicação minuciosa dos exercícios, graduação racional dos esforços e aprimoramento antes de avançar para séries mais complexas.

Vale ressaltar que as quedas em GACRO são comuns, devido às adaptações de ritmo e transferências de peso entre os parceiros e à identificação do centro de gravidade nas figuras, porém, queda não pode ser entendida como sinônimo de acidente.

\section{PIRÂmides}

Conhecer os diversos tipos de pirâmides é essencial para ampliar as possibilidades de atuação, aumentar a criatividade e o acervo motor dos alunos.

Santana et al. (1996) sugerem uma proposta de organização dos conteúdos da GACRO. De acordo com estes autores, as formações humanas se subdividiriam em:

- Formações básicas (figuras corporais e pirâmides humanas);

- Formações grupais (figuras corporais e pirâmides humanas);

- Estruturas completas.

Entendam-se formações básicas por formações realizadas em duplas ou trios, formações grupais por formações de 4 a 9 integrantes e formações de grandes grupos por formações com mais de 9 integrantes.

As figuras corporais podem ser conceituadas como formações estáticas realizadas entre todos os componentes do grupo, sem estar um em cima do outro. Já as pirâmides humanas implicam sempre

Movimento, Porto Alegre, v. 14, n. 02, p. 155-180, maio/agosto de 2008. 
em estrutura de duas alturas, geralmente sendo a base maior que a parte superior, nas quais o peso dos volantes recai sobre intermediários e/ou bases.

As figuras corporais podem ser subdivididas em figuras de contrabalanceio, de apoio, de equilíbrio, de apoio invertido e figuras combinadas.

As pirâmides humanas podem ser classificadas de acordo com o:

- Posicionamento de seus bases: deitado, em quatro apoios e em dois apoios;

- Número de bases: de dois bases e de um base.

As figuras e pirâmides podem ser de composição aberta, nas quais os ginastas encontram-se na mesma linha, ou fechada, nas quais as bases estão fechadas, formando um círculo, quadrado, entre outras, construindo uma base sólida para outras alturas.

Elas também podem ser classificadas, partindo-se do critério de altura das mesmas em comparação com as partes do corpo dos ginastas:

- Pirâmides de solo: são pirâmides onde o ponto de apoio do volante está abaixo da linha da cintura do base.

- Pirâmides de meia altura: são pirâmides onde o ponto de apoio do volante está na linha da cintura do base.

- Pirâmides de primeira altura: são pirâmides onde o ponto de apoio do volante está na linha dos ombros do base.

- Pirâmides de uma altura e meia (somente trios e quartetos): são pirâmides onde um atleta está com seu ponto de apoio na linha da cintura, e o outro na linha dos ombros.

- Pirâmides de segunda altura (somente trios e quartetos): são pirâmides onde o volante está com o ponto de apoio na linha dos ombros do intermediário e o mesmo está com o ponto de apoio na linha dos ombros do base.

- Pirâmides de duas alturas e meia (somente quartetos): são as pirâmides onde um atleta está com o ponto de apoio na linha da cintura e os outros na linha dos ombros.

Mavimento, Porto Alegre, v. 14, n. 02, p. 155-180, maio/agosto de 2008. 
- Pirâmides de terceira altura (somente quartetos): são as pirâmides nas quais intermediários e volante estão com os pontos de apoios na linha dos ombros.

\subsection{Evolução pedagógica das figuras}

O passo seguinte ao conhecimento dos tipos de pirâmides é saber que existe um nível crescente de complexidade entre elas e sugere-se que as mesmas sejam apresentadas de forma gradativa, da mais simples para a mais complexa, constituindo uma evolução pedagógica.

Criley (1984) mostra-se como um grande colaborador para as questões pedagógicas da GACRO, por ser o único autor encontrado que sugere alguns princípios pedagógicos para a evolução da aprendizagem das figuras e pirâmides estáticas:

- Iniciar com pirâmides de posições baixas e de apoios centrais;

- Passar para posições altas e de apoios centrais;

- Passar para posições baixas e de apoios nas extremidades;

- Por último, passar para posições altas e de apoios nas extremidades.

\section{Considerações Finais}

Ao reapresentar a GACRO para alguns e apresentá-la para a maioria dos leitores, tem-se a intenção de despertar o interesse dos profissionais da Educação Física para a implementação desta modalidade esportiva e de suas amplas possibilidades tanto no contexto escolar quanto no da iniciação e aperfeiçoamento esportivo.

As características da GACRO, aqui apresentadas, legitimam-na como uma prática rica e altamente positiva para o contexto escolar e dos clubes. Isto porque pode oferecer inúmeras possibilidades de exploração motora, além de estimular as noções espaciais e rítmicas, as diversas capacidades físicas e principalmente a criatividade, tanto em relação à composição de figuras como à elaboração de pequenas

Movimento, Porto Alegre, v. 14, n. 02, p. 155-180, maio/agosto de 2008. 
coreografias. Quanto aos aspectos sócio-afetivos, destacamos a cooperação, a confiança em si e nos outros, a autonomia e o prazer que permeiam todo este processo. Ao inserir situações-problema adequadas neste contexto, permite-se que o aluno seja estimulado a demonstrar sua capacidade de resolução corporal. Desse modo, ainda que de forma precária, podem nascer os primeiros momentos de prazer e alegria na prática esportiva, gerando sensações de sucesso que se estendem à vida como um todo, fato que se mostra importante para a formação do cidadão e relevante na atual sociedade.

A aplicação da GACRO na escola e no clube possibilita uma aula diferenciada diante dos desafios que são propostos, aliando teoria e prática e ensinando os alunos sobre determinados conceitos, procedimentos e atitudes que a modalidade oferece. É importante, também, que as propostas sejam variadas em oportunidades e que apresentem diferentes meios para a prática, a qual pode ser desenvolvida com alunos de diferentes estruturas físicas, preservando a heterogeneidade das turmas e favorecendo a inclusão.

Tal modalidade carece de uma disseminação de suas práticas e de estudos sobre seus diversos aspectos que dêem base a esta prática. Este artigo de revisão teve a intenção de apresentar a GACRO de forma global e deixar pistas de alguns aspectos que podem ser estudados, "abrindo portas" para novas pesquisas acadêmicas posteriores e propiciando os requisitos básicos para a ampliação dos conhecimentos dos professores e para o enriquecimento de sua prática pedagógica. Sem dúvida, os grandes beneficiados serão os alunos, que terão a oportunidade de experimentar esta modalidade gímnica que muito pode contribuir para a criatividade, assim como para a formação humana dos praticantes.

Mavimento, Porto Alegre, v. 14, n. 02, p. 155-180, maio/agosto de 2008. 


\section{Rediscovering the acrobatic gymnastic}

Abstract: Acrobatic Gymnastic, the youngest modality of the universe of competitive Gymnastic, shows itself of great pedagogical worth, although it is hardly ever studied in the Academic environment and presents few records of knowledge acquired along of the years. This revision article aims to promote the rediscovering of the Gymnastic Acrobatic, as an object of academic studies, practice of sports and content of school physical education. Therefore, the scenery of the modality in the World, Acrobatic Gymnastic historical trajectory, its characteristics and particularities and also some pedagogical principles shall be approached based on the most relevant authors for the subject. Keywords: Acrobatic Gymnastic. Review literature. Sports: history.

Redescubriendo la gimnásia acrobática

Resumen: La Gimnasia Acrobática, la más joven modalidad del universo gimnástico competitivo, mostrase de gran valor pedagógico, sin embargo tenga sido poco estudiada en lo ambiente académico y presente pocos registros de sus conocimientos adquiridos a lo largo de los tiempos. Este artigo de revisión logra impulsar lo redescubrimiento de la Gimnasia Acrobática, como objeto de estudios académicos, practica deportiva y contenido de la educación física escolar. Para esto, serán abordados lo escenario de la modalidad en el mundo, su trayectoria histórica, sus características y especificidades y algunos principios pedagógicos con base en los autores más relevantes para el tema.

Palabras-clave: Gimnasia Acrobática. Literatura de revisión. Desportes: historia.

\section{REFERÊNCIAS}

ALMEIDA, Antônio. Ginástica Acrobática: iniciação na escola e no clube. Revista Horizonte, Lisboa, v. 11, n. 62, p. 28, jul./ago. 1994.

ASTOR, Charles. Metodologia do ensino da Ginástica Acrobática. Rio de Janeiro: Ministério da Educação e Cultura, [1954?].

BOELSEMS, Paula. Characteristics of sports acrobatics competition exercises. International Gymnast, Norman, v. 24, p. 52, apr. 1982.

Movimento, Porto Alegre, v. 14, n. 02, p. 155-180, maio/agosto de 2008. 
BRASIL. Lei 9.615, de 24 de março de 1998. Institui normas gerais sobre desporto e dá outras providências. Diário Oficial da República Federativa do Brasil, Brasília, DF, 25 de março de 1998. Disponível em: < http://www81.dataprev.gov.br/sislex/ paginas/42/1998/9615.htm>. Acesso em: 30 set. 2005.

BROZAS, Maria Paz; NOWOTYNSKI, Witek. Los portés como componente técnico específico del acrosport. Rendimentodeportivo.com, n. 2, 2002. Disponível em: < www.rendimentodeportivo.com/n002/artic011.html.> Acesso em: 08 mar. 2007.

SOARES, Carmem Lúcia et al. Metodologia do ensino de Educação Física. São Paulo: Cortez, 1992.

CONFEDERAÇÃO BRASILEIRA DE GINÁSTICA. Estatuto CBG - 2005. Disponível em: <http://www.cbginastica.com.br/le_noticia.asp?id=639 > Acesso em: 30 set. 2005.

CRILEY, Dick. COULTON, J. Safety in sports acrobatics. International Gymnast, Norman, v. 26, p. 62-65, apr. 1984. 1982. Sports Acrobatics. International Gymnast, Norman, v. 24, p. 42, mar.

DOUGLAS, Alexander. Sports Acrobatics and cheerleaders. International Gymnast, Norman, p. 42, mar. 1982.

FEDERAÇÃO INTERNACIONAL DE GINÁSTICA. Código de pontuação de pontuação da Ginástica Acrobática 2005-2008. Disponível em: <http://www.figgymnastics.com/doc/code-acro-0705-ezip>. Acesso em: 30 set. 2005.

FEDERAÇÃO NORTE AMERICANA DE GINASTICA. What is Acrobatic Gymnastics? Disponível em: <http://www.usa-gymnastics.org/acro/aboutacro.html>. Acesso em: 30 set. 2005.

FEDERAÇÃO PAULISTA DE GINÁSTICA. Apresenta informações sobre as manifestações ginásticas. Disponível em: <http://www.ginasticas.com.br.> Acesso em: 05 out. 2005 .

FODERO, J. M.; FURBLUR, E. E. Creating gymnastic pyramids and balances. Champaign: Leisure, 1989.

FRIEND, Jed. Let's keep growing! Acro interest is increasing rapidly. International Gymnast, Norman, v. 32, p. 41, sep. 1990a.

Sports Acrobatics: the missing link in the overall gymnastics picture. International Gymnast, Norman, v. 32, p. 54, ago. 1990b.

GALLAHUE, David. L.; OZMUN, Jonh. C. Compreendendo o desenvolvimento motor: bebês, crianças, adolescentes e adultos. 3. ed. São Paulo: Phorte, 2005.

HUGHES, Mike.; CROWLEY, A. Success in sports acrobatics as a function of complexity of skills and time. Journal of Human Movement Studies, New Jersey, v. 40, n. 3, p. 161-170, 2001.

Mavimento, Porto Alegre, v. 14, n. 02, p. 155-180, maio/agosto de 2008. 
LANGLADE, Alberto; LANGLADE, Nelly Rey de. Teoria general de la gimnasia. Buenos Aires: Stadium, 1970.

LEGUET, Jacques. As ações motoras em ginástica esportiva. São Paulo: Manole, 1987.

MERIDA, Fernanda. Os fundamentos da ginástica acrobática. In: NUNOMURA, M. Curso modular fundamentos das modalidades esportivas ginásticas. São Paulo: Escola de Educação Física e Esportes da USP: 2004. CD-ROM.

NISSEN, George. Twenty advantages sports acrobatics has over gymnastics. International Gymnast, Norman, v. 33, p. 36-37, jan. 1991.

POZZO, Thierry; STUDENY, Christophe. Théorie et practique des sports acrobatiques. Paris: Vigot, 1987.

SANTANA, Mercedes; BEDOYA, Jesús López; PANADERO, Francisco Bautista. EI Acrosport en la Escuela. Barcelona: Inde, 1996.

SANTOS, Cícero Rodrigues. Gymnica: 1000 exercícios: ginástica olímpica, trampolim acrobático, mini-trampolim, acrobática. Rio de Janeiro: Sprint, 2002.

SOARES, Carmem Lúcia. Imagens da educação no corpo: estudo a partir da ginástica francesa do século XIX. Campinas: Autores associados, 1998.

SOUZA, Elizabeth Paoliello Machado de. O universo da ginástica: evolução e abrangência. In: Coletânea do $\mathrm{V}$ encontro de história do esporte, lazer e educação física. Maceió, 1997b.

Ginástica geral: uma área do conhecimento da Educação Física. 1997. 163 p. Tese (Doutorado) - Faculdade de Educação Física, Universidade Estadual de Campinas, Campinas, 1997a.

Mavimento, Porto Alegre, v. 14, n. 02, p. 155-180, maio/agosto de 2008. 